\title{
Anion Exchange Renders Hydrophobic Capsules and Cargoes Water-Soluble
}

\author{
Edmundo G. Percástegui, ${ }^{\dagger}$ Jesús Mosquera, ${ }^{\dagger}$ and Jonathan R. Nitschke*
}

\begin{abstract}
Control over the solubility properties of container molecules is a central challenge in host-guest chemistry. Here we present a simple anion exchange protocol that allows the dissolution in water of various hydrophobic metal-organic container molecules, prepared using $\mathrm{Fe}^{\prime \prime}$-templated subcomponent self-assembly. Our process involved the exchange of hydrophobic trifluoromethanesulfonate anions for hydrophilic sulfate; the resulting water-soluble cages could be rendered water-insoluble through reverse anion exchange. Notably, this strategy allowed cargoes within capsules to be brought into water, including polycyclic aromatics and complex organic drugs; hydrophobic effects appeared to enhance binding, as many of these cargoes were not bound in non-aqueous media. Studies of the scope of this method revealed that cages containing tetratopic and tritopic ligands were more stable in water, whereas cages with ditopic ligands disassembled.
\end{abstract}

Chemical activity in living organisms takes place within isolated nano-compartments that subdivide the aqueous medium of a living cell. Selective encapsulation of substrates in these confined spaces leads to alteration of their physicochemical properties, and regulates their reactivity, to either prevent or facilitate subsequent transformations. ${ }^{1}$ Watersoluble metal-organic capsules displaying well-defined inner hydrophobic pockets constitute a class of containers that have proven useful as molecular devices for substrate storage and transport, ${ }^{2}$ and as reaction vessels to catalytically accelerate chemical processes. ${ }^{3}$ Although the engineering of synthetic receptors has seen tremendous progress in the last decade, ${ }^{4}$ further development of functional supramolecular capsules that mimic and rival natural organisms is hindered by the lack of straightforward methods to prepare metal-organic host assemblies that operate in aqueous solution. Laborious synthetic modifications to append solubilizing groups or incorporate cationic elements into organic building blocks have often been required to ensure aqueous solubility of the final assembly. ${ }^{5}$

Recently, the subcomponent self-assembly method has been employed by others ${ }^{6}$ and ourselves ${ }^{7}$ to prepare functional architectures through the synergistic formation of dynamiccovalent $(\mathrm{C}=\mathrm{N})$ imine $^{8}$ and coordinative $\mathrm{N} \rightarrow$ Metal bonds. ${ }^{9}$ Our group has made use of subcomponent self-assembly to prepare metal-organic capsules in aqueous solution, when sufficiently water-soluble subcomponents were used. ${ }^{7}$

[*] Dr. E. G. Percástegui, Dr. J. Mosquera, Prof. J. R. Nitschke Department of Chemistry, University of Cambridge

Lensfield Road, Cambridge, CB2 1EW (UK)

E-mail: jrn34@cam.ac.uk

Homepage: http://www.nitschkegroup-cambridge.com/

$\left.{ }^{\dagger}\right] \quad$ These authors contributed equally to this work.

Supporting information and the ORCID identification numbers for the authors of this article are given via a link at the end of the document.
We had inferred that the use of subcomponents having at least slight water-solubility would be necessary in order to generate water-stable capsules, because of the dynamic nature of the $\mathrm{C}=\mathrm{N}$ and $\mathrm{N} \rightarrow$ Metal linkages: If the small equilibrium population of a free subcomponent reaches a concentration at which it is no longer soluble, precipitation will ensue. This precipitation will drive backwards the formation equilibrium of a self-assembled structure, leading to a failure to form, or to decomposition.

Here we show that certain self-assembled cages, constructed from highly insoluble subcomponents, can be dissolved in water, even though these structures cannot be prepared in water. These cages are kinetically inert due to the many linkages that cooperatively hold them together, enabling their host-guest properties to be studied in aqueous solution.

Our method consists of exchanging the less hydrophilic trifluoromethanesulfonate (triflate, $\mathrm{OTf}^{-}$) counterions of hydrophobic cages formed in acetonitrile for the more hydrophilic sulfate. This strategy was applied to a series of capsules representative of those designed by our group. Importantly, none of these capsules could be prepared directly from iron(II) sulfate, which has been the only successful method employed until now. ${ }^{7}$

Ion exchange proved reversible in some cases, allowing the recovery of the previous water-insoluble assembly without perturbing the cationic cage framework. The robustness of these structures thus contrasts with the structural reconfigurations often observed as responses to anionic chemical signals in several examples of supramolecular coordination systems, ${ }^{10}$ including capsules prepared through subcomponent selfassembly. ${ }^{11}$ To the best of our knowledge, this study represents the first example of anion exchange used to transform waterinsoluble capsules into water-soluble ones.

We initially selected cubic $\mathrm{Fe}{ }_{8} \mathrm{~L}_{6}$ cage 1.0Tf, whose faces are defined by fourfold-symmetric Zn-porphyrin $\mathbf{A}$, and whose corners constitute six-coordinate low-spin Fell ions (Figure 1). It is soluble in DMF and $\mathrm{MeCN}$ but insoluble in $\mathrm{H}_{2} \mathrm{O}$ or $\mathrm{MeOH}$. Cage 1.OTf has been shown to encapsulate large aromatic guests in DMF. ${ }^{12}$

When either tetrabutylammonium (TBA) or potassium sulfate (24 equiv per cage) was added to a solution of 1.OTf in $\mathrm{MeCN}$, the sulfate salt $\mathbf{1} \cdot \mathbf{S O}_{4}$ precipitated as a magenta solid that is soluble in water and partially soluble in $\mathrm{MeOH}$. Electrospray Mass Spectrometry (ESI-MS) analyses were consistent with the formulation of $\mathbf{1} \cdot \mathbf{S O}_{4}$ as an octasulfate. Additionally, its ${ }^{1} \mathrm{H}$ NMR spectrum in $\mathrm{D}_{2} \mathrm{O}$ is consistent with the $O$-symmetric structure previously reported, and no fluorine signal was observed by ${ }^{19} \mathrm{~F}$ NMR, consistent with the absence of triflate ions. DOSY measurements are consistent with the formation of a single species, and the absence of aggregates of 1.5O $\mathbf{S O}_{4}$. Attempts to directly prepare derivative $\mathbf{1} \cdot \mathbf{S O}_{4}$ from its components and $\mathrm{FeSO}_{4}$ in diverse solvents and mixtures (DMF, 
1:1 DMF/ $\mathrm{H}_{2} \mathrm{O}, \mathrm{MeCN}, 1: 1 \mathrm{MeCN} / \mathrm{H}_{2} \mathrm{O}$, or $1: 1 \mathrm{MeOH} / \mathrm{H}_{2} \mathrm{O}$ ) were unsuccessful, affording solids that were insoluble in water and in the attempted solvent mixture.

No degradation of $\mathbf{1} \cdot \mathbf{S O}_{4}$ was observed by NMR for aqueous solutions at lower $(0.2 \mathrm{mM})$ and higher $(15 \mathrm{mM})$ concentrations after two months at $25^{\circ} \mathrm{C}$. However, $\mathbf{1} \cdot \mathbf{S O}_{4}$ was observed to decompose at higher temperatures, as evidenced by the observation of free aldehyde in the ${ }^{1} \mathrm{H}$ spectrum after heating to $50{ }^{\circ} \mathrm{C}$ for $6 \mathrm{~d}$ (Figure S5), and by the observation of solid precipitate. Almost complete decomposition occurred after $16 \mathrm{~h}$ at $70^{\circ} \mathrm{C}$.

Anion exchange was reversible; 1.0Tf precipitated upon addition of LiOTf to a water solution of $\mathbf{1} \cdot \mathrm{SO}_{4}$ (Figure S6). The complete OTf $\rightarrow \mathrm{SO}_{4} \rightarrow \mathrm{OTf}$ anion exchange cycle was carried out multiple times, with $92-94 \%$ recovery by weight per cycle.
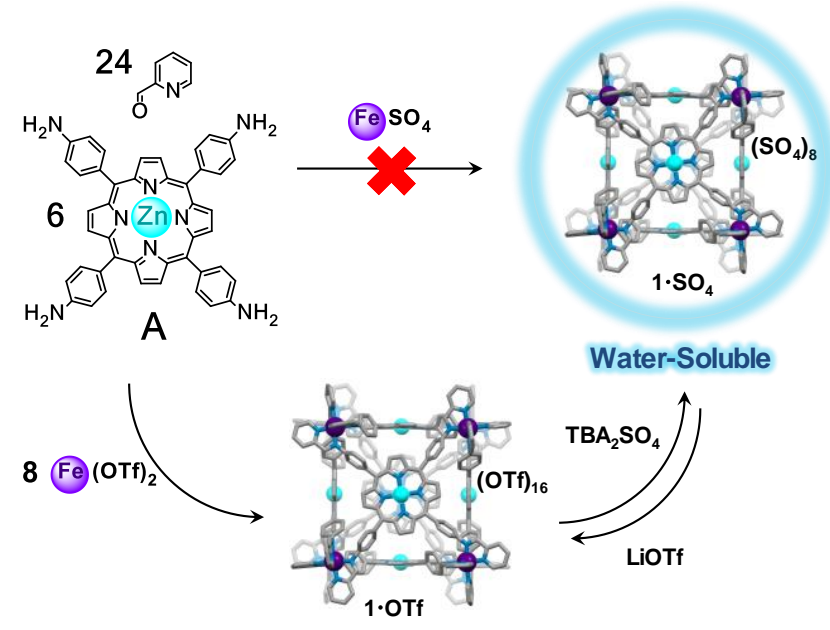

Water-Insoluble

Figure 1. Preparative self-assembly of 1.OTf and reversible anion exchange to obtain the water-soluble derivative $\mathbf{1} \cdot \mathrm{SO}_{4}$, the direct synthesis of which was not possible.

Other anions were also screened to test their ability to form water-soluble salts of 1 . Addition of TBACl, TBABr, TBAl, or $\mathrm{TBANO}_{3}$ (24 equiv per cage) to 1.0Tf in acetonitrile led to a color change and precipitation over $12 \mathrm{~h}$ with disappearance of ${ }^{1} \mathrm{H}$ NMR peaks corresponding to $\mathbf{1}$.

Cube 2, containing free-base porphyrin faces in place of the Zn-porphyrin motifs of $\mathbf{1}$ (Figure 2), was then prepared in order to probe the generality of aqueous host-guest chemistry involving analogs of cubic host 1 . As we had previously observed 2.0Tf to bind three coronene (Cor) guests in its cavity, ${ }^{12}$ we chose the [Cor ${ }_{3} \subset \mathbf{2}$. OTf] adduct as to compare the behavior of $\mathbf{2}$ in water and acetonitrile.

Following the reported method, ${ }^{12}$ complex [Cor $\left.{ }_{3} \subset 2.0 T f\right]$ was prepared in DMF and then transformed into the corresponding sulfate salt via anion exchange. The host-guest [Cor ${ }_{3} \subset \mathbf{2} \cdot \mathbf{S O}_{4}$ ] cube was soluble in water at millimolar concentrations, and this solution appeared stable over weeks at room temperature. Degradation was only observed after $48 \mathrm{~h}$ at $50^{\circ} \mathrm{C}$.

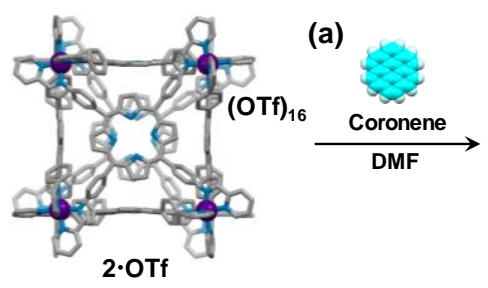

$\begin{aligned} & \text { (c) } \\ & \text { TBA }_{2} \mathrm{SO}_{4}\end{aligned} \mid$ LiOTf

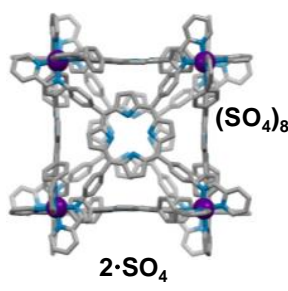

(d)

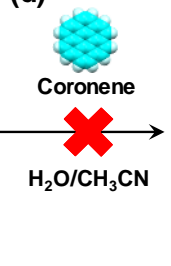

$\begin{aligned} & \text { (b) } \\ & \text { TBA }_{2} \mathrm{SO}_{4}\end{aligned} \mid \uparrow$ LiOTf
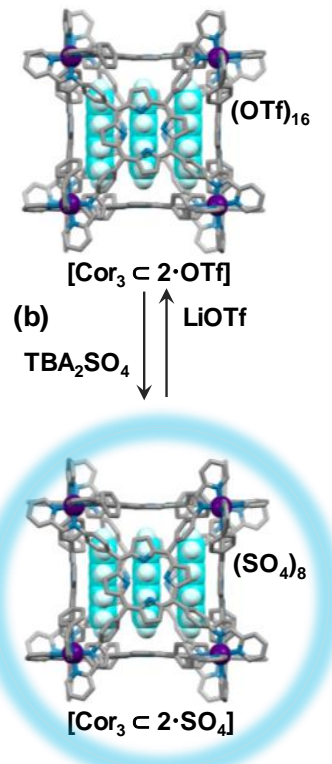

Water-Soluble

Host-Guest Complex

Figure 2. Anion exchange sequence using a host-guest complex. (a) Encapsulation of three coronenes inside 2.OTf took place in DMF. (b) Coronene molecules were transported into water following addition of $\mathrm{TBA}_{2} \mathrm{SO}_{4}$ and back into acetonitrile by addition of LiOTf. (c) Empty 2. OTf was converted into sulfate derivative; however, (d) encapsulation of coronene was not observed in water or aqueous mixtures.

Cube $\left[\mathrm{Cor}_{3} \subset \mathbf{2} \cdot \mathrm{SO}_{4}\right]$ was converted back into $\left[\mathrm{Cor}_{3} \subset\right.$ 2.0Tf] following treatment with lithium triflate. No decomposition was observed during this process: ESI-MS and NMR analyses indicated that the coronene cargo remained intact through each step of this cycle (Figure S13). In contrast, encapsulation was not observed if $\mathbf{2} \cdot \mathbf{S O}_{4}$ was treated with coronene in water or in 1:1 $\mathrm{MeCN} / \mathrm{H}_{2} \mathrm{O}$. During each step of the sequential anion exchange, neither disruption of the cage scaffold nor guest release was observed. These observations confirm the robustness of the cubic framework in both the presence and absence of a cargo, demonstrating the promise of anion exchange for the transport of hydrophobic molecules in water.

To further probe the scope and limitations of our method, other water-insoluble tetrahedral capsules were also subjected to a similar anion exchange treatment. We have reported enantiopure $\mathrm{Fe}_{4} \mathrm{~L}_{4}$ cage [OTf $\subset$ 3.OTf] (Figure 3a), which contains four $\mathrm{Fe}^{\text {Il }}$ centers bridged by four threefold-symmetric ligands formed by aldehyde $\mathbf{C},{ }^{13}$ as well as the $\mathrm{Fe}^{11}{ }_{4} \mathrm{~L}_{6}$ capsule [OTf $\subset$ 4.OTf] (Figure 3b), containing six twofold-symmetric bisbidentate pyridylimine ligands derived from dialdehyde $\mathbf{D}$, each defining a tetrahedron edge. ${ }^{11}$ Both cages host an internallybound triflate anion (Figure 3 ).

Treatment of the triflate salts of both $\mathbf{3}$ and $\mathbf{4}$ with $\mathrm{TBA}_{2} \mathrm{SO}_{4}$ in acetonitrile yielded the corresponding water-soluble sulfates. NMR and ESI-MS analyses showed that in both, [OTf $\subset$ 3. $\mathrm{SO}_{4}$ ] and [OTf $\subset 4 \cdot \mathrm{SO}_{4}$ ], a single triflate remains inside the cavity after anion exchange. 
After $48 \mathrm{~h}$ at room temperature or after heating the sample at $50{ }^{\circ} \mathrm{C}$ for $12 \mathrm{~h}$, the ${ }^{1} \mathrm{H}$ NMR spectrum of [OTf $\subset 3 \cdot \mathbf{S O}_{4}$ ] in $\mathrm{D}_{2} \mathrm{O}$ developed a single new set of small signals, assigned to "empty" cage following release of the encapsulated triflate anion. Notably, this triflate guest remained kinetically trapped in aqueous solution. After two days at room temperature, the mixture of empty and filled cages had approached equilibrium, showing a 1:9 empty:filled cage ratio as estimated by ${ }^{1} \mathrm{H}$ NMR integration (Figures S17-S18). The addition of LiOTf (10 equiv per cage) in acetonitrile regenerated the initial [OTf $\subset$ 3. OTf] capsule after 16 $\mathrm{h}$ at room temperature or $6 \mathrm{~h}$ at $50^{\circ} \mathrm{C}$ (Figures S19-S20).

In contrast, [OTf $\subset \mathbf{4} \cdot \mathbf{S O}_{4}$ ] was observed to disassemble in water, although anion exchange occurred cleanly to generate it. Nearly $60 \%$ of the cage was observed to hydrolyze after $4 \mathrm{~h}$ at $20{ }^{\circ} \mathrm{C}$ (Figure S21). We infer that the binding of ligands based upon tritopic $\mathbf{C}$ is likely to be more robust than the binding of ligands based on ditopic $\mathbf{D}$, leading to more stable cages.

a)

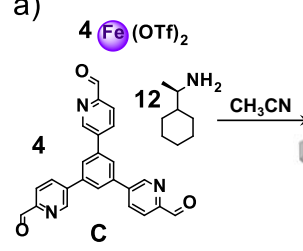
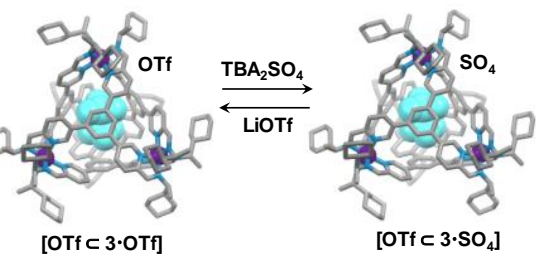

b)
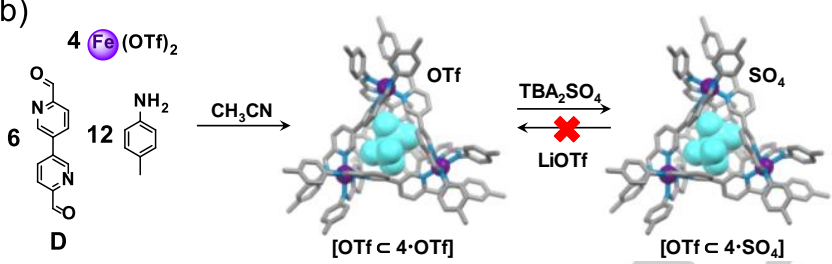

Figure 3. Anion metathesis applied to tetrahedral cages. (a) Anion exchange

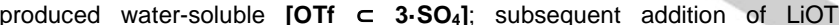
regenerated the initial [OTf $\subset 3.0 T$ ] . (b) Cage [OTf $\subset 4 . \mathrm{SO}_{4}$ ] was obtained following treatment with $\mathrm{TBA}_{2} \mathrm{SO}_{4}$, but the reverse reaction was not successful due to cage disassembly in water. Encapsulated triflate guests (depicted in blue and spacefilling mode) remained in the cavity during the anion metathesis process.

To further test cage stability, we applied our anionmetathesis method to tetrahedral cages $\mathbf{5}$ and $\mathbf{6}$, constructed from tritopic face-capping aniline $\mathbf{E}$ and ditopic aniline $\mathbf{F}$, respectively (Figure 4). Although addition of $\mathrm{TBA}_{2} \mathrm{SO}_{4}$ to an acetonitrile solution of either cage generated a dark precipitate that we infer to contain the sulfate salt of the respective cage, the dissolution of these precipitates in water led to capsule decomposition and rapid precipitation of trianiline $\mathbf{E}$ or dianiline $\mathbf{F}$

The differing behaviors in water of the sulfate salts of cages 1-6 allowed the identification of two key factors that influenced their stabilities in aqueous solution. First, more multitopic ligands, which bridged between more metal centers, led to more stable cage structures. Second, formylpyridinebased multitopic subcomponents produced more stable structures than aniline-based subcomponents. We infer that coordination of ligand pyridine groups to metal centers during the hydrolysis and condensation of imine linkages may help to keep intermediate species in solution.

These observations may enable the design of selfassembled materials of practical use in drug delivery or cargo transport. For instance, we envisage that the shorter half lives of capsules constructed from dialdehyde subcomponents might constitute the basis for developing systems that could selectively bind a drug and undergo controlled disassembly in vivo to release a therapeutic payload. ${ }^{2 c, 14}$

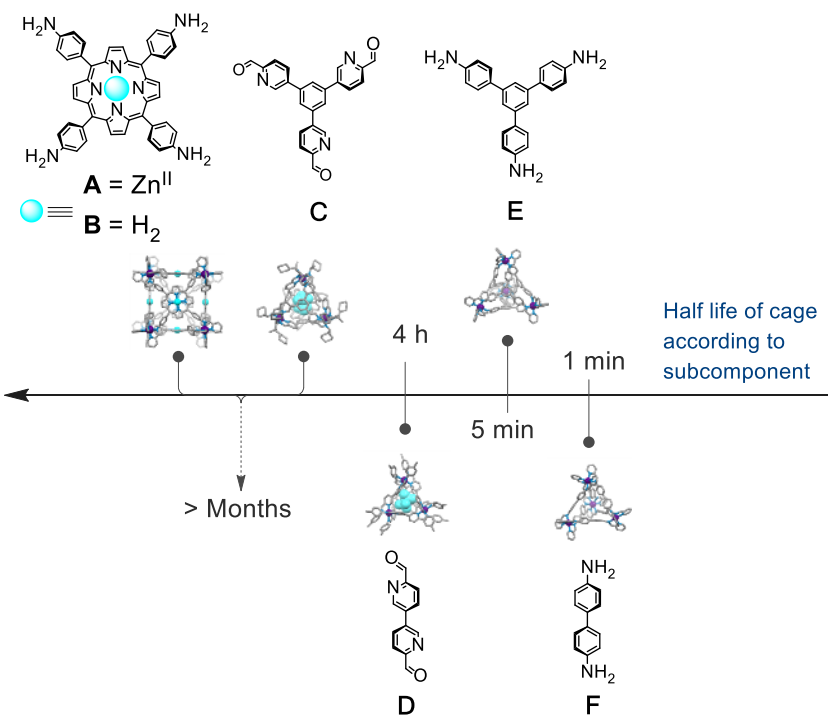

Figure 4. Subcomponents $\mathbf{A}-\mathbf{F}$ and the relative half lives of their corresponding capsules in water.

Finally, we carried out preliminary aqueous host-guest studies with $\mathbf{1} \cdot \mathbf{S O}_{4}$. The molecules listed in Figure 5 were screened as guests. Each prospective guest was added in water (50-70 mM guest in $\mathrm{D}_{2} \mathrm{O}$ or $\mathrm{CD}_{3} \mathrm{OD}$ ) to an aqueous solution of 1. $\mathrm{SO}_{4}(200-250 \mu \mathrm{M})$. The molecules that were inferred to bind (Figure 5a) engendered broadening and shifting of inward-facing host ${ }^{1} \mathrm{H}$ NMR peaks $(|\Delta \delta|>0.12 \mathrm{ppm}$, Figures S24-S30), consistent with binding in fast exchange on the NMR time scale along with shifting of guest resonances for the water soluble caffeine and inosine molecules $(|\Delta \delta|>0.90 \mathrm{ppm})$. Given the large volume of cube 1 (ca. $1300 \AA^{3}$ ) relative to guest size, modelling suggests that multiple guests may be simultaneously binding to $\mathbf{1} \cdot \mathbf{S O}_{\mathbf{4}}$, precluding the straightforward determination of stoichiometry and strength of host-guest association. For those molecules that were inferred not to bind (Figure $5 b$ ), no changes were observed in the ${ }^{1} \mathrm{H}$ NMR spectra during the titration experiments or after stirring with a solid amount of prospective guests $(|\Delta \delta|<0.01 \mathrm{ppm}$, Figures S31-S34). From examining the two groups of molecules depicted on Figure 5 , we infer that guest binding may require conformational flexibility, so that guests may enter the pores of the cubic framework. Biologically relevant products such as caffeine, inosine, and an antibiotic macrolide were thus bound by 1 in water, along with steroids of biological and therapeutic relevance. 
Remarkably, none of the guests shown in Figure 5 showed NMR evidence of binding to 1.OTf in acetonitrile (Figures S35S38). This observation suggests that the hydrophobic effect plays an essential role in driving binding. ${ }^{15}$

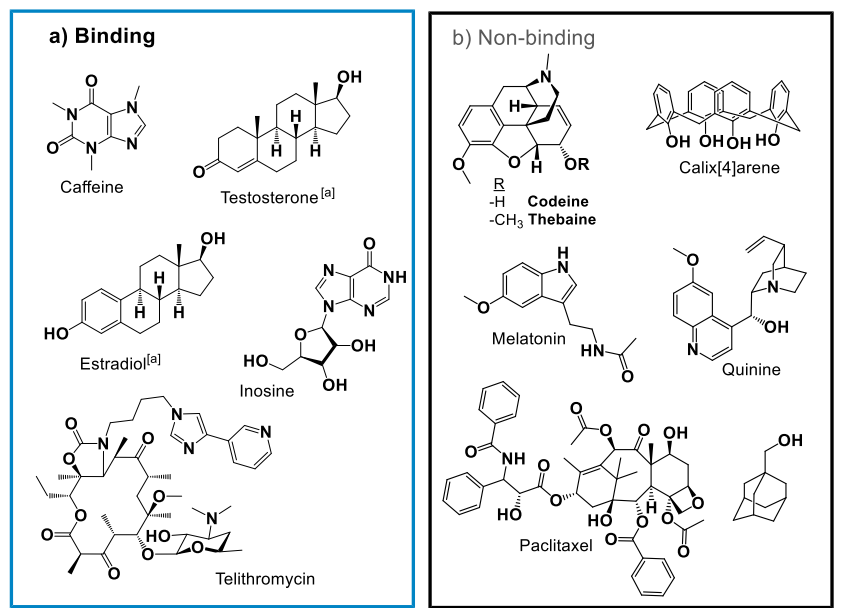

Figure 5. Prospective guests tested for cubic capsule $\mathbf{1} \cdot \mathbf{S O}_{4}$ in aqueous solution: (a) guests for which fast-exchange interaction was observed; (b) compounds that were not encapsulated. [a]Binding was studied in 1:4 $C D_{3} \mathrm{OD}: \mathrm{D}_{2} \mathrm{O}$ to avoid precipitation of guest due to low solubility.

In summary, we have demonstrated that the combination of subcomponent self-assembly and anion metathesis offers a powerful means of generating water-soluble supramolecular capsules, which otherwise would require laborious synthetic modifications. The examination of a diverse collection of assemblies provides a means to predict whether a given capsule may be stable in water following anion metathesis. The collection of newly-water-soluble hosts now accessible allows for new means of interaction with biological systems through the selective binding of biologically-relevant molecules.

\section{Acknowledgements}

This work was supported by the European Research Council (695009) and the UK Engineering and Physical Sciences Research Council (EPSRC, EP/M008258/1). The authors thank the Cambridge University Chemistry NMR facility for performing some NMR experiments and the EPSRC National Mass Spectrometry Facility at Swansea University for carrying out high resolution analyses. E.G.P. acknowledges CONACyT-Mexico for postdoctoral funding (263689). J.M. acknowledges postdoctoral fellowship support from Fundación Ramón Areces.

Keywords: supramolecular chemistry $\cdot$ self-assembly $\bullet$ watersoluble capsules $\cdot$ anion exchange $\bullet$ host-guest chemistry

[1] M. J. Wiester, P. A. Ulmann, C. A. Mirkin, Angew. Chem. Int. Ed. 2011, 50, 114-137; Angew. Chem. 2011, 123, 118-142.

[2] a) T. Sawada, M. Yoshizawa, S. Sato, M. Fujita, Nat. Chem. 2009, 1, 53-56. b) V. M. Dong, D. Fiedler, B. Carl, R. G. Bergman, K. N.
Raymond, J. Am. Chem. Soc. 2006, 128, 14464-14465. c) F. Schmitt, J. Freudenreich, N. P. E. Barry, L. Juillerat-Jeanneret, G. Süss-Fink, B. Therrien, J. Am. Chem. Soc. 2012, 134, 754-757. d) B. Roy, A. K. Ghosh, S. Srivastava, P. D'Silva, P. S. Mukherjee, J. Am. Chem. Soc. 2015, 137, 11916-11919. e) J. Sahoo, R. Arunachalam, P. S. Subramanian, E. Suresh, A. Valkoen, K. Rissanen, M. Albrecht, Angew. Chem. Int. Ed. 2016, 55, 9625-9629; Angew. Chem. 2016, 128, 97779781.

[3] a) W. Cullen, M. C. Misuraca, C. A. Hunter, N. H. Williams, M. D. Ward Nat. Chem. 2016, 8, 231-236. b) D. M. Dalton, S. R. Ellis, E. M. Nichols, R. A. Mathies, F. D. Toste, R. G. Bergman, K. N. Raymond, J. Am. Chem Soc. 2015, 137, 10128-10131. c) Z. Laughrey, B. C. Gibb, Chem. Soc. Rev. 2011, 40, 363-386. d) M. Yoshizawa, M. Tamura, M. Fujita, Science 2006, 312, 251-254. e) Sk. Jasimuddin, T. Yamada, K. Fukuju, J. Otsuki, K. Sakai, Chem. Commun. 2010, 46, 8466-8468.

[4] a) T. R. Cook, P. J. Stang, Chem. Rev. 2015, 115, 7001-7045. b) L. Xu, Y.-X. Wang, L.-J. Chen, H.-B. Yang, Chem. Soc. Rev. 2015, 44, 21482167.

[5] a) M. Whitehead, S. Turega, A. Stephenson, C. A. Hunter, M. D. Ward, Chem. Sci., 2013, 4, 2744-2751. b) B. Roy, E. Zangrando, P. S. Mukherjee, Chem. Commun. 2016, 52, 4489-4492. c) K. Yazaki, S. Yoshihisa, M. Akita, M. Yoshizawa, Chem. Eur. J. 2016, 22, 1755717561. d) N. Kishi, Z. Li, K. Yoza, M. Akita, M. Yoshizawa, J. Am. Chem. Soc. 2011, 133, 11438-11441.

[6] a) P. F. Kuijpers, M. Otte, M. Dürr, I. Ivanović-Burmazović, J. N. H. Reek, B. de Bruin, ACS Catal. 2016, 6, 3106-3112. b) H. Bunzen, Nonappa, E. Kalenius, S. Hietala, E. Kolehmainen, Chem. Eur. J. 2013 19, 12978-12981. c) J. Roukala, J. Zhu, C. Giri, K. Rissanen, P. Lantto, V.-V. Telkki, J. Am. Chem. Soc. 2015, 137, 2464-2467. d) Y. Wu, X.-P Zhou, J.-R. Yang, D. Li, Chem. Commun. 2013, 49, 3413-3415. e) D.-H. Ren, D. Qiu, C.-Y. Pang, Z. Li, Z.-G. Gu, Chem. Commun. 2015, 51, 788-791. f) X. Wu, N. Xu, Z. Zhu, Y. Cai, Y. Zhao, D. Wang, Polym. Chem. 2014, 5, 1202-1209. g) P. D. Frischmann, V. Kunz, V Stepanenko, F. Würthner, Chem. Eur. J. 2015, 21, 2766-2769. h) X. P. Zhou, Y. Wu, D. Li, J. Am. Chem. Soc. 2013, 135, 16062-16065. i) D. Lewing, H. Koppetz, F. E. Hahn, Inorg. Chem. 2015, 54, 7653-7659. j) J. Domer, J. C. Slootweg, F. Hupka, K. Lammertsma, F. E. Hahn, Angew. Chem. Int. Ed. 2010, 49, 6430-6433; Angew. Chem. 2010, 122, 65756578.

[7] a) D. Zhang, T. K. Ronson, J. Mosquera, A. Martinez, L. Guy, J. R. Nitschke, J. Am. Chem. Soc. 2017, DOI: 10.1021/jacs.7b02950. b) J. L. Bolliger, A. M. Belenguer, J. R. Nitschke, Angew. Chem. Int. Ed. 2013, 52, 7958-7962; Angew. Chem. 2013, 125, 8116-8120. c) P. Mal, D. Schultz, K. Beyeh, K. Rissanen, J. R. Nitschke, Angew. Chem. Int. Ed. 2008, 47, 8297-8301; Angew. Chem. 2008, 120, 8421-8425.

[8] a) D. Beaudoin, F. Rominger, M. Mastalerz, Angew. Chem. Int. Ed. 2017, 56, 1244-1248; Angew. Chem. 2017, 129, 1264-1268. b) M Mastalerz, Angew. Chem. Int. Ed. 2010, 49, 5042-5053; Angew. Chem. 2010, 122, 5164-5175. c) C. Bravin, E. Badetti, F. A. Scaramuzzo, G. Licini, C. Zonta, J. Am. Chem. Soc. 2017, 139, 6456-6460.

[9] J. R. Nitschke, Acc. Chem Res. 2007, 40, 103-112.

[10] a) S. Freye, J. Hey, A. Torras-Galán, D. Stalke, R. Herbst-Irmer, M. John, G. H. Clever, Angew. Chem. Int. Ed. 2012, 51, 2191-2194; Angew. Chem. 2012, 124, 2233-2237. b) W. Wang, Y.-X. Wang, H.-B. Yang, Chem. Soc. Rev. 2016, 45, 2656-2693. c) L. Liu, G. Lyu, C. Liu, F. Jiang, D. Yuan, Q. Sun, K. Zhou, Q. Chen, M. Hong, Chem. Eur. J. 2017, 23, 456-461. d) R. Custelcean, Chem Soc. Rev. 2014, 43, 18131824. e) K. S. Min, M. P. Suh, J. Am. Chem. Soc. 2000, 122, 6834 6840. f) Y. Wang, P. Cheng, Y. Song, D.-Z. Liao, S.-P. Yan, Chem. Eur. J. 2007, 13, 8131-8138. g) S. Löffler, J. Lübben, L. Krause, D. Stalke, B. Dittrich, G. H. Clever, J. Am. Chem. Soc. 2015, 137, 1060-1063.

[11] I. A. Riddell, Y. R. Hristova, J. K. Clegg, C. S. Wood, B. Breiner, J. R. Nitschke, J. Am. Chem. Soc. 2013, 135, 2723-2733.

[12] W. Meng, B. Breiner, K. Rissanen, J. D. Thoburn, J. K. Clegg, J. R. Nitschke, Angew. Chem. Int. Ed. 2011, 50, 3479-3483; Angew. Chem. 2011, 123, 3541-3545. 
[13] A. M. Castilla, N. Ousaka, R. A. Bilbeisi, E. Valeri, T. K. Ronson, J. R. Nitschke, J. Am. Chem. Soc. 2013, 135, 17999-18006.

[14] a) Y.-R. Zheng, K. Suntharalingam, T. C. Johnstone S. J. Lippard, Chem. Sci. 2015, 6, 1189-1193. b) B. Therrien, Chem. Eur. J. 2013, 19, 8378-8386. c) J. E. M. Lewis, E. L. Gavey, S. A. Cameron, J. D. Crowley, Chem. Sci. 2012, 3, 778-784. d) N. P. E. Barry, O. Zava, P. J. Dyson, B. Therrien, Chem. Eur. J. 2011, 17, 9669-9677.

[15] a) E. Krieg, M. M. C. Bastings, P. Besenius, B. Rybtchinski, Chem. Rev. 2016, 116, 2414-2477. b) E. Krieg, B. Rybtchinski, Chem. Eur. J. 2011 $17,9016-9026$. 


\section{Entry for the Table of Contents}

\section{COMMUNICATION}

Sulfate is Great: Anion exchange enables a variety of large and hydrophobic self-assembled capsules to be dissolved in water, where they encapsulate a wide range of guests that may not be bound in acetonitrile.

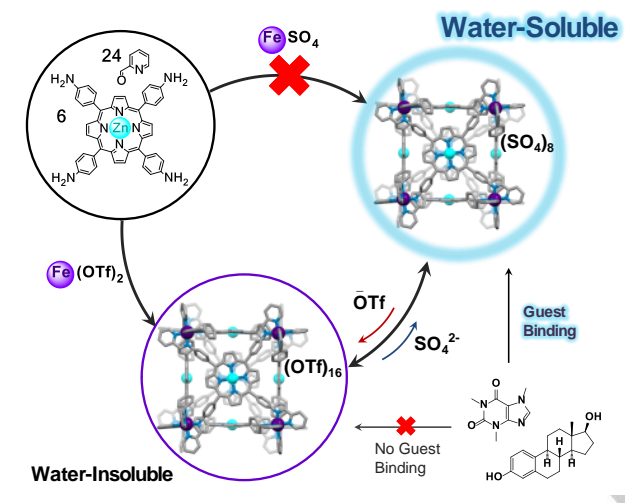

Edmundo G. Percástegui, Jesús Mosquera, and Jonathan $R$. Nitschke*

Page No. - Page No.

Anion Exchange Renders Hydrophobic Capsules and Cargoes Water-Soluble 